\title{
AN EXPERIENCE OF THE USE OF “MOODLE" AT ISCAP A Case study
}

\author{
Paula Peres, Manuel da Silva, Sandra Ribeiro \\ Polytechnical Institute of Oportol,School of Accounting and Administrationt, Rua Jaime Lopes Amorim s/n, \\ Oporto, Portugal
}

Keywords: $\quad$ E-learning; Blended-Learning; Learning Management Systems (LMS).

\begin{abstract}
Nowadays, a constant concern with the quality level of the educative/educational offers in Institutions of Higher Education is verifiable. In order to accomplish that, they should acquire the capacity/capability to adapt to the new characteristics of their target audience and the new communication and information technologies that emerge every day. In such context, and as an answer to the upcoming demands, ISCAP (School of Accounting and Administration has initiated a project called PAOL - Projecto de Apoio On-Line (On-Line Support Project). Its main goal is to provide support to the implementation of computer assisted teaching, it being constituted by human and material resources (software - an open source LMS, called Moodle, and hardware). This article intends to reveal the knowledge acquired throughout the experience in the use of the LMS Moodle at ISCAP, in the second semester of the 2004/2005 school year.
\end{abstract}

\section{INTRODUCTION}

The quality of the educative offers is a growing criterion used by the students in the choice of higher education institutions.

Information and communication technologies are in constant evolution, providing an increasing number of job offers, with which the students are more familiar. For this reason they demand a greater effort by the teachers and the institutions of education, thus looking forward to explore these technologies at an educational level.

Because of this social pressure, the institutions of higher education need to act proactively in order to provide suitable educational offers, adapted to the new requirements and with the capacity to follow change.

In this context, and as an answer to the emerging demands, ISCAP (School of Accounting and Administration) began a project called PAOL Projecto de Apoio On-Line (http://paol.iscap.ipp.pt). Its main goal is to provide support to the implementation of computer-assisted teaching, it being constituted by human resources (Coordinating Unit of the Project) and material resources (software - OpenSource LMS called "Moodle" and hardware) that intend to stimulate the use of information and communication technologies, by teachers and students, in an harmonious and integrated form. The pedagogical innovation and the temporal flexibility of individual and collaborative study support of our students present themselves as the vectors of this project. These converge on the quality improvement of the educational offers.

The objective of using an on-line LMS is to allow the students, through the use of the Internet, access to the subjects taught in class and to provide new learning activities (individual and in group). It does not intend to be a substitute of in-class lessons, but an additional support to the students.

\section{PLANNING}

For the project's implementation a model called "Elearning P3 Model" was adapted. For Khan, Badrul (Badrul, H. K.,2004) the implementation process of an e-learning project is constituted by the planning, designing, development, execution and maintenance, and involves people, processes and products.

Although this model is usually presented for large e-learning projects, it also predicts possible adaptations to projects of smaller and medium dimensions. It defines the responsibilities and functions of the different interveners because, in the case of smaller projects, that might lead to accumulation of functions. 


\section{OBJECTIVES}

The main objective of this project was to explore technologies as a pedagogical resource and to innovate the teaching/learning process. The students' preparation for their professional life was also an objective that was pursued, as well as their engagement in the study of the subjects. It was important to motivate the students, to simplify their access to knowledge, to create Internet using habits in study and work activities, to make available, in useful time, diversified material to back up study and to provide different forms of learning, according to the various individual learning styles.

\section{INTERVENERS}

The first phase of this project, which occurred in the second semester of the 2004/2005 school year, included the participation of all the teachers that were interested in developing their own individual projects, in the scope of their subjects/classes.

\section{TECHNOLOGICAL CONTEXT}

\begin{abstract}
Moodle (Modular Object-Oriented Dynamic Learning Environment) was the chosen technological LMS. It is a tool, designed by Martin Dougiamas, (Western Australia), to create courses based on the Internet. It is an LMS available in 70 languages, including Portuguese. It is a continuous project to support educational socio-constructivism.

In Portugal, its usage has been increasing, thus justifying the opening of an open space to share experiences. Moodle is an LMS that offers a set of activities that are adaptable to the contents of the most diversified subjects. It has several activities that can be used differently as educational instruments. It is possible to insert texts and necessary documentation for the subjects, to suggest assignments, promote discussion forums and to create term glossaries in a cooperative form. The assessment and self-evaluation of knowledge is done through the pages of lessons and questionnaires.
\end{abstract}

\section{ACTIVITIES}

The activities began with the development of the proposal document of the On-line Support Project (PAOL) and the creation of the project image. This was followed by its presentation to the school community in a session that occurred in the beginning of the second semester of the 2004/2005 school year.

As to the LMS, three Workshops were carried out, one for the elements of the Coordinating Unit and Technical Support, Pedagogical Direction and Contents Management Direction, and the other two for the teachers of the institution. These workshops included the presentation of some suggestions as to the use of the LMS.

The next stage was composed by the definition of a strategic plan to implement IT according to the curricula, the educational environment and the declaration of Bologna. The computer science teachers of ISCAP took the responsibility of the students' training while users of Moodle.

Parallel to these activities, the project coordinating team offered continuous support to the production of on-line contents and the use of Moodle.

A site was also developed - available at http://www.iscap.ipp.pt/paol, - to divulge the main objectives of the project, activities and the national and international events on computer-assisted teaching. It was equally intended to use the site to give support to the user and to promote the reflection of the intrinsic concepts of the On-line Support Project and computer-assisted teaching, such as: $e$ learning, blended-learning, learning objects, LMS, etc

The Coordinating Unit has also developed two guides with performance specifications of the LMS, one meant for the teachers and another for the students; these are available in the Project site.

On the 9th of May, 2005 a debate about the theme e-learning was promoted, in a conference called "The non-attended teaching in the University of Aveiro in initial training and postgraduate courses: genesis, experience and lessons" having as invited speaker the Professor António Moreira, PhD.

At the end of the semester an inquiry was carried out to evaluate the implementation process of the project. The participants were the students and teachers that had participated in the project.

At this moment an eventual participation in European projects is being studied. Investigation in this area is also underway. 


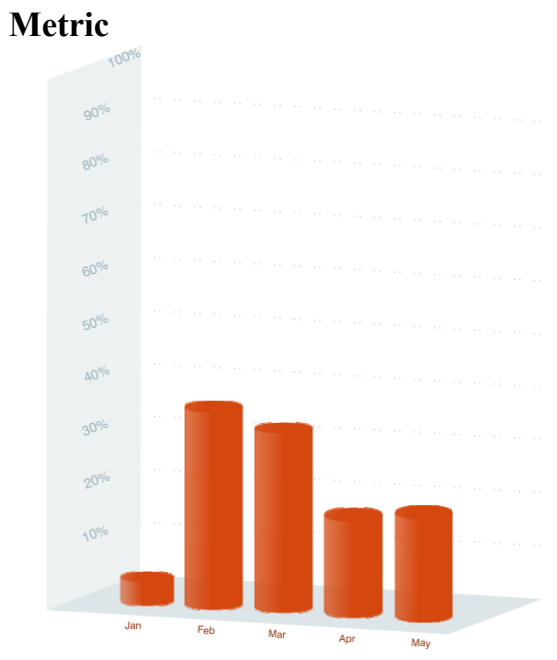

Figure 1: Total Number of accesses to PAOL.

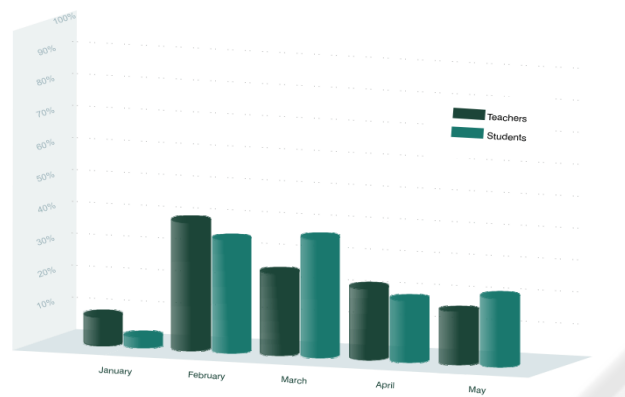

Figure 2: Number of student and teacher accesses. Student and Teacher accesses to Moodle.

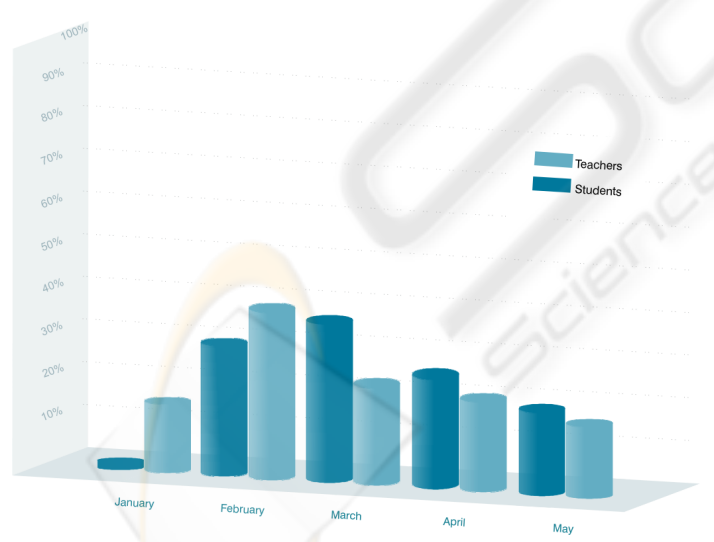

Figure 3: Number of user registration in the LMS.

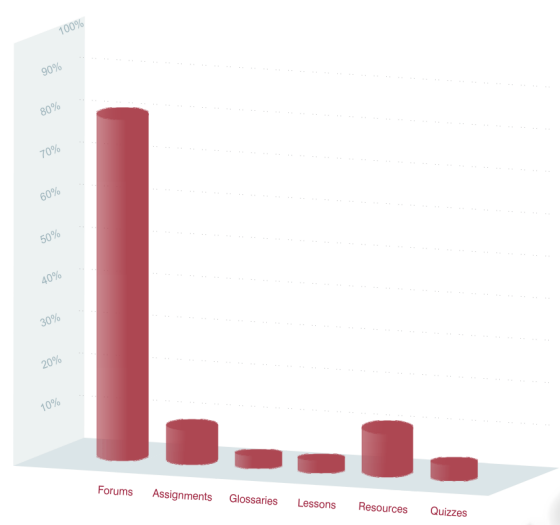

Figure 4: Moodle Activities.

Results of the evaluation inquiries on the implementation process of PAOL:

\section{$\underline{\text { Subjects in which there were answers }}$}

Total of subjects analysed: $37 \%$

Corresponding population: $30 \%$

Answers obtained from the teachers

Total of consulted teachers: 28

Corresponding population: 24

\section{COURSE PERCENTAGE OF ON-LINE SUBJECTS 2ND SEMESTER \\ Concerning the number of subjects in each course

$\begin{array}{lr}\text { Accounting and Administration } & 13 \\ \text { International Commerce } & 12 \\ \text { Languages and Secretarial Skills } & 26 \\ \text { Marketing } & 12\end{array}$

Figure 5: Course Percentage of on-line subjects.

\section{EVALUATION OF THE PROCESS}

It was possible to verify, from the analysis done on the use of the LMS at ISCAP, that since its implementation, from January until April 2005, that the number of accesses reached its maximum in February and March. 
It must be said, that the workshops for teachers had been carried out on the 10th and 25th of January and on the 2nd of February of 2005. This possibly justifies the few accesses during January. During the Easter holidays, that occurred between the 23rd of March and 3rd of April, the LMS was not available, for maintenance reasons.

During January and February the teachers accessed the LMS more times. These values are justified by the necessity of previous configuration and the insertion of contents onto their subjects, to use the LMS later on in their classes.

Between January and March there was an increasing number of registrations, stabilizing, with a small decrease in value in April.

The activities used more often by the teachers are the resources, the forums and assignments, and the ones that register less use are the glossaries, the lessons and the quizzes.

The resources are the main activity chosen by the teachers, probably because it is the easiest way to access and provide documentation to students, therefore eliminating the necessity of physical delivery.

The forums were also very used by teachers essentially for the accomplishment of group work and for the debate of themes related to their subject.

Teachers also used activities like assignments, probably because they are simple to suggest, to program and to correct. Perhaps due to the time of preparation, lessons and quizzes were not as used. However, teachers do recognize their importance.

The evaluation process only took into account those teachers that used PAOL. Among those, only the classes that were not delivered to the same group of students were taken into account in the second phase of the analysis. The first stage clearly demonstrated that the highest number of subjects online occurred in the Languages and Secretarial Skills course, with 12 different subjects contemplated. This constituted $32 \%$ of the total number of subjects online.

As to the total number of teachers using PAOL in ISCAP: it seems to be a considerable number of teachers that have adhered to the production of online contents in such a short time.

\section{$\underline{2^{\text {nd }} \text { Stage }- \text { Evaluation - Questionnaire analysis }}$}

As we've said, the analysis of the questionnaires was based on the subjects and users that weren't repeated (as there are several subjects in the same course, it would be not correct to consider all the questionnaires answered, because we'd be duplicating the results).

As to the number of teachers using PAOL, some of them duplicated the contents because they had the same subject in different courses. It was also noted that some didn't answer the questionnaires appropriately, or didn't answer them at all, so we just considered a part.

The number of teachers using PAOL was considerable right from the beginning (a total of 28 teachers out of 220) and everyday more and more teachers are adhering. However only 21 out of the 28 answered the questionnaires appropriately. There were 37 subjects on-line, 30 of which were considered in this study.

The evaluation criteria were as follows:

- User's profile

- Type of Internet access, conditions and user's resources

- Evaluation of on-line contents (subjects)

- LMS performance evaluation

- Users overall level of satisfaction with LMS

In this study we asked if the contents available on-line for each subject would be sufficient without the traditional classes, so we could foresee the possibility of migrating the subjects to e-learning courses. However, $61,49 \%$ of the students (as opposed to $31,51 \%$ ) claimed that the contents were not sufficient. The main reasons given to explain their position, was considerable importance given to human intervention as this gave them the possibility of contacting the teachers easily (they seemed concerned with the teachers availability).

Traditional classes were preferred. Students were also asked to compare traditional classes with on-line lessons. $48,98 \%$ of the students referred to them as the same, $26,19 \%$ classified on-line as being worst while $24,83 \%$, considered them better.

\section{STUDENTS' PERCEPTIONS}

The analysis of the questionnaires allowed us to verify that $87,79 \%$ of the students, were satisfied with the LMS (only 12,21\% expressed a different opinion). Some difficulties were noted in terms of access $(31,72 \%)$, file uploads $(13,1 \%)$ and file downloads $(7,59 \%)$. Students also expressed the existence of unnecessary steps to locate the contents, and difficulties in using forums. They were not satisfied with the organization teachers used; claimed to have an excessive number of contents available, and expressed difficulty in using the LMS. $8,28 \%$ of the students questioned commented on the fact that the LMS wasn't available during the Easter holidays.

The importance given to this initiative and its impact in students' academic life was also considered. $96,49 \%$ of the students questioned considered this initiative extremely important as 
opposed to $3,51 \%$, which considered the Project as irrelevant.

\section{TEACHERS' PERCEPTIONS}

As to the perception of the teachers, a good adhesion of the teachers from all areas was noted. The analysis of the questionnaires denounced associated difficulties in uploading files $(19,05 \%)$, accessing the LMS $(9,52 \%)$ and establishing group work (as workshops weren't working efficiently). The lack of computers at the students' disposal and the fact that a synchronous tool (chats) was not available was also noted. $38,1 \%$ of the teachers didn't reply and $9,52 \%$ found no difficulties.

In spite of the revealed difficulties, $90,48 \%$ of the teachers said to be satisfied while $9,52 \%$ didn't answer the question.

\section{CONCLUSIONS AND RECOMMENDATIONS}

The evaluation that took place after the first semester showed that the adhesion of the students was good and that the use of the LMS by the teachers functioned as a stimulation for the use of the Internet as a working tool.

Therefore, we can confirm that the use of a technological LMS could constitute a chance of innovation in the teaching/learning process, and can be an interesting leverage for the creation of new educational contexts.

To stimulate the use of the LMS and to give continuity to PAOL, new workshops and involvement of marketing students to divulge the project as innovative and productive in the teaching/learning process of the school is foreseen in the next school year.

We also foresee the befalling of seminars and further work on the reflection on the use of Information and Communication Technologies, namely in the production and publication of educational contents on the Internet, contemplating students' individual learning styles.

\section{REFERENCES}

Badrul, H. K., 2004, 'The People - Process - Product Continuum in E-Learning: The E-Learning P3 Model', Issue of Educational Technology, vol. 44, no.5, pp.3344
Beaudin, B., 1999, 'Keeping Online Assynchronous Discussions on Topic' Journal of Assynchronous Learning Networks, vol. 3, no. 2

Conford, J, Pollock, N., 2002, 'The University Campus as a "resourcefull constraint": process and practice in the construction of the virtual university', in M. Lea \& K. Nicoll. Distributed Learning: Social and Cultural approaches to practice, RoutledgeFalme, New York, pp. 170-181.

Elearningeuropa 2005, Programa para a integração efectiva das TIC nos sistemas europeus de educação e formação, viewed 23 June 2005

$<$ http://elearningeuropa.info/index.php?page $=$ doc\&doc_id $=4552 \&$ docIng $=16 \& \mathrm{vtxt}=0>$

Freitas, L., Freitas, C., 2003, Aprendizagem Cooperativa, Edições ASA, Porto.

Miranda, L., Morais, C., Dias, P., Almeida, C., 2001, ‘ Ambientes de Aprendizagem na web: Uma Experiência com fóruns de discussão, in II Conferência Internacional Challenges' 2001/ Desafios' 2001, Universidade do Minho, Portugal.

Karayan, S, Crowe, J., 1997, Students perceptions of Electronic Discussion Groups, T.H.E Journal, vol. 24, no. 9 , viwed 26 July 2005 ,

$<$ http://www.thejournal.com/magazine/vault/a1367.cfm>.

Pallof, R., Pratt, K., 1999, Building Learning Communities in cyberspace: effective strategies for the online classroom, Jossey-Bass Publishers, San Francisco

PLS Ramboll, 2004, Studies in the context of e-Learning Initiative. Virtual Models of European Universities (lot 1), Draft Final Report to the EU Comission, DG Education and Culture, PLS Ramboll Management $\mathrm{A} / \mathrm{S}$.

Ramos, A, Freitas, C., 1999, 'Gostei, aprendi, diverti-me, perspectivas, dos alunos acerca da utilização educativa das tecnologias', in Conferência Internacional Challenges'99/ Desafios'99, Universidade do Minho, Portugal.

Sousa, R. R., 2005, Uma proposta construtivista para a actualização de Tecnologias na Educação, in Educação, aprendizagem e Tecnologia - Um paradigma para professores do século XXI, 1st edn , Edições Sílabo.

Zemsky, R, Massy, W., 2004, Thwarted Innovation: What happened to e-learning and why, University of Pensylvania: The Learning Aliance 